Journal of Computer Science 8 (9): 1473-1477, 2012

ISSN 1549-3636

(C) 2012 Science Publications

\title{
Speed Control of Switched Reluctance Motor Using New Hybrid Particle Swarm Optimization
}

\author{
${ }^{1}$ T.V. Mahendiran, ${ }^{2} \mathrm{~K}$. Thanushkodi and ${ }^{3} \mathrm{P}$. Thangam \\ ${ }^{1}$ Department of EEE, \\ Coimbatore Institute of Engineering and Technology, Coimbatore, India \\ ${ }^{2}$ Akshaya College of Engineering and Technology, Coimbatore, India \\ ${ }^{3}$ Department of CSE, Sri Ramakrishna Engineering College, Coimbatore, India
}

\begin{abstract}
Problem statement: The main objective of this research is to obtain the speed control of switched reluctance motor with minimum settling time and without overshoot. Approach: A new algorithm has been developed with the combination of differential evolution and particle swarm optimization and applied for speed control of switched reluctance motor under sudden change in speed. Also speed control of switched reluctance motor was obtained by other artificial intelligence methods such as fuzzy logic controller, fuzzy PI controller and particle swarm optimization based tuning of fuzzy PI controller. Matlab/Simulink environment was used for the simulation. Results: Results are discussed and tabulated based on the performance of the controllers. Conclusion: From the comparison of all above methods, the algorithm has given better results in speed response than other controllers.
\end{abstract}

Key words: Switched reluctance motor, differential evolution, Particle Swarm Optimization (PSO), fuzzy logic controller, fuzzy PI controller, PWM inverter

\section{INTRODUCTION}

Most of the manufacturing units in the world depend on electric motors for their production. More than half of the energy is consumed by the electrical motor in the industries. Hence, all the engineers and manufacturers seek the better control techniques to improve the control and efficiency of the motor. This is the major reason for more research works concentrating on efficient control of motor. The essential characteristics of electrical drive system are accurate and fast recovery in speed response from any disturbance. Due to rapid development of the power electronics, it plays an important role in control of electrical machinery during the last five decades. The power electronics devices are the most important elements in the conversion of electrical energy above billions of kilowatts in an efficient, clean, compact and robust manner for convenient utilization.

The SRMs are attractive solutions for variable applications requiring high performances such as variable speed control, servo motor drive, jet engine starter and generator (Shun-Chung and Liu, 2011). The features of SRM include simplicity, robustness, low manufacturing cost, high starting torque, high speed and high efficiency (Miller, 1993; Lawrenson et al., 1980). It requires only a simple converter circuit with reduced number of switches due to unidirectional current requirements (Pollock and Williams, 1990).

These advantages make the SRM an economical alternative to PMBLDC motor, squirrel cage induction motor and DC series motor (Moghbelli et al., 1991). The SRM can be operated in the four quadrants and it is very much suitable for hazardous areas like explosion proof machinery, traction mining and domestic applications. Presently, much research work focus on SRM control and torque smoothness in order to make it compete with fully controlled dc and ac drives (Nagel and Loranz, 2000). Analog control has been proven to be the best control mechanism for any industrial drive. But, classical controllers (i.e., PID controllers) require exact mathematical model of the systems and are very sensitive to parameter variations (Santana et al., 2002; Ahmed et al., 1997). Therefore, the use of classical controllers does not meet the requirements for robust performance. The introduction of artificial intelligence (Krohling et al., 1997; Sousa and Bose, 1994) has brought a new era in the industrial drive. Various AI based heuristic controls have shown a good prospect to bring robustness and adaptive nature in constant speed variable torque or constant torque variable speed drive applications (Kukolj et al., 2000). So the superior performance of Artificial Intelligence (AI) based

Corresponding Author: Mahendiran, T.V., Department of Electrical and Electronics Engineering,

Coimbatore Institute of Engineering and Technology, Coimbatore-641109, Tamilnadu, India 
controllers urged power system and power electronic engineers to replace conventional speed control circuit with intelligent speed controllers. Fuzzy logic is one of the artificial intelligence techniques, but its applications are more recent than other experts systems. It gives smooth output control even for huge variations in input variables. It provides an opening for control system which is normally considered to be not feasible for automation. It can also be hybrid with other algorithms to solve the complex problems. Fuzzy logic has been successfully implemented in modeling, process control and military science. Fuzzy logic controller is the most suitable to design the controller for difficult mathematical model due to nonlinearity and impression.

Particle swarm optimization became a popular algorithm due to its simplicity and usage of few variables (Kennedy and Eberhart, 1995). It has been successfully implemented in many areas such as neural network, fuzzy logic, control of power electronics drives and image processing and system identification in bio mechanics. Differential evolution is another global optimization algorithm which is applied for speed control application. Several enhancements are continuously developed from the Differential evolution for further optimization.

In this research, fuzzy controller, fuzzy PI controller, PSO optimized fuzzy PI controller and PDODE optimized fuzzy PI controller have been proposed for the speed control of Switched Reluctance Motor.

\section{MATERIALS AND METHODS}

Fuzzy logic controller: Fuzzy Logic Controllers (FLCs) are smart control systems characterized by a set of linguistic statements based on specialist knowledge. Fuzzy Logic Controllers have been broadly used for imprecise, non-linear and complex systems (Narmadha and Thyagarajan, 2010). A simple FLC consists of four major elements: a fuzzifier, rule base, an fuzzy inference engine and a defuzzifier. The fuzzifier converts real system variables into fuzzy variables. The inference unit provides the necessary connection between the controller input and output fuzzy sets. The rule base expressed in the form of If-then rules is used by the inference unit. The defuzzifier takes the results of fuzzy reasoning and produces a new real control action.

Fuzzy PI controller design: A typical PI controller is described by Eq. 1:

$$
u(t)=K\left(e(t)+\frac{1}{T_{i}} \int_{0}^{t} e(\tau) d \tau\right)
$$

where, $\mathrm{K}$ is the gain of PI controller, $\mathrm{Ti}$ is an integral constant, e(t) is an error signal, e $(\mathrm{t})=\mathrm{r}(\mathrm{t})-\mathrm{y}(\mathrm{t}), \mathrm{r}(\mathrm{t})$ is the desired value, $\mathrm{y}(\mathrm{t})$ is the output from process and $\mathrm{u}(\mathrm{t})$ is the output from controller, is derived from $\mathrm{u}(\mathrm{t})$ as given in Eq. 2:

$u^{\prime}(t)=K\left(e^{\prime}(t)+\frac{1}{T_{i}} e(t)\right)$

This is translated in to discrete form, to get the equation for action value change of discrete PI controller given in Eq. 3:

$\Delta \mathrm{u}(\mathrm{k})=\mathrm{K}\left(\Delta \mathrm{e}(\mathrm{k})+\frac{1}{\mathrm{~T}_{\mathrm{i}}} \mathrm{e}(\mathrm{k})\right)$

The above Equation can also be written as Eq. 4:

$\Delta \mathrm{u}(\mathrm{k})=\mathrm{K} \frac{1}{\mathrm{~T}_{\mathrm{i}}}\left(\Delta \mathrm{e}(\mathrm{k}) \mathrm{T}_{\mathrm{i}}+\frac{1}{\mathrm{~T}_{\mathrm{i}}} \mathrm{e}(\mathrm{k})\right)$

Thus, the input and output variables of fuzzy PI controller can be defined in Eq. 57.

$$
\begin{aligned}
& \mathrm{E}(\mathrm{k})=\mathrm{e}(\mathrm{k}) \cdot \mathrm{G}_{\mathrm{e}} \\
& \mathrm{CE}(\mathrm{k})=\mathrm{ce}(\mathrm{k}) \cdot \mathrm{G}_{\mathrm{cc}} \\
& \Delta \mathrm{i}(\mathrm{k})=\Delta \mathrm{I}(\mathrm{k}) \cdot \mathrm{G} \Delta \mathrm{i}
\end{aligned}
$$

where, $\mathrm{e}(\mathrm{k})$ is the error between reference speed and rotor speed, ce $(\mathrm{k})$ is the change of error in speed, $\mathrm{I}(\mathrm{k})$ is the output of the fuzzy logic controller and $\mathrm{G}_{\mathrm{e}}, \mathrm{G}_{\mathrm{ce}}$ and $\mathrm{G} \Delta \mathrm{i}$ are scaling factors. In the case of a PI type FLC, the actual value of the controller output is obtained by Eq. 8 as follows:

$\mathrm{u}(\mathrm{k})=\mathrm{u}(\mathrm{k}-1)+\Delta \mathrm{u}(\mathrm{k})$

where, $\mathrm{u}(\mathrm{k})$ is the controller output, $\mathrm{u}(\mathrm{k}-1)$ the $(\mathrm{k}-1)^{\mathrm{th}}$ instant controller output and $\Delta \mathrm{u}(\mathrm{k})$ is the incremental change in controller output, which is determined by the rules.

If $\mathrm{e}$ is $\mathrm{E}$ and $\Delta \mathrm{e}$ is $\Delta \mathrm{E}$, then $\Delta \mathrm{u}$ is $\Delta \mathrm{u}(\mathrm{k})$.

PI- Fuzzy controller has less sensitivity to load changes, where higher sensitivity to the change of the input voltage is observed. The FLC has two inputs, the error $\mathrm{e}(\mathrm{k})$ and change of error $\Delta \mathrm{e}(\mathrm{k})$, which are defined by $\mathrm{e}(\mathrm{k})=\mathrm{r}(\mathrm{k})-\mathrm{y}(\mathrm{k}), \Delta \mathrm{e}(\mathrm{k})=\mathrm{e}(\mathrm{k})-\mathrm{e}(\mathrm{k}-1)$, where $\mathrm{r}$ and $\mathrm{y}$ denote the applied set point input and plant output, respectively. Indices $\mathrm{k}$ and $\mathrm{k}-1$ indicate the present state and the previous state of the system, respectively. The output of the FLC is the incremental change in the control signal, $\Delta \mathrm{u}(\mathrm{k})$. 


\section{J. Computer Sci., 8 (9): 1473-1477, 2012}

Particle swarm optimization: Particle Swarm Optimization (PSO) is an algorithm for finding optimal regions of complex search space through interaction of individuals in a population of particles. PSO algorithm, originally introduced in terms of social and cognitive behavior by Kennedy and Eberhart (1995); Del Valle et al., 2008) has been proven to be a powerful competitor to other evolutionary algorithms such as genetic algorithms. PSO is a population based stochastic optimization technique and well adapted to the optimization of nonlinear functions in multidimensional space. PSO has received significant interest from researchers studying in different research areas and has been applied to several real-world problems. PSO algorithm simulates social behavior among individuals (particles) flying through multidimensional search space, each particle representing a single intersection of all search dimensions. The particles evaluate their positions relative to a global fitness at every iteration and companion particles share memories of their best positions and then use those memories to adjust their own velocities and positions. At each generation, the velocity of each particle is updated, being pulled in the direction of its own previous best solution and the best of all positions (global).

\section{Algorithm:}

Step1: In every iteration, each particle is updated by following two best values, Personal best and Global best.

Step2: After finding the two best values, the particle updates its velocity and positions with following Eq. 9 and 10.

$$
\begin{aligned}
& \mathrm{v}[\mathrm{i}]=\mathrm{v}[\mathrm{i}]+\mathrm{c} 1 * \operatorname{rand}(\mathrm{i}) *(\operatorname{pbest}[\mathrm{i}]-\operatorname{present}[\mathrm{i}]) \\
& +\mathrm{c} 2 * \operatorname{rand}(\mathrm{i}) *(\operatorname{gbest}[\mathrm{i}]-\operatorname{present}[\mathrm{i}]) \\
& \operatorname{present}[\mathrm{i}]=\operatorname{present}[\mathrm{i}]+\mathrm{v}[\mathrm{i}]
\end{aligned}
$$

$\mathrm{v}[\mathrm{i}]=$ The particle velocity,

present [i] $\quad=$ The current particle (solution)

pbest $[\mathrm{i}]$ and gbest[i] = Defined as stated before .

rand (i) $\quad=$ Random number between $(0,1)$

$\mathrm{c} 1, \mathrm{c} 2=$ Learning factors. Usually $\mathrm{c} 1=\mathrm{c} 2=2$.

Implementation of PSODE-Fuzzy PI Controller: In this study, a time domain criterion is used for evaluating the PI controller. A set of good control parameters $\mathrm{P}$ and I can yield a good step response that will result in performance criteria minimization in the time domain. These performance criteria in the time domain include the overshoot, rise time, settling time and steady-state error. Therefore, the performance criterion is defined by Eq. 11. (Gaing, 2004; Nasri et al., 2007):

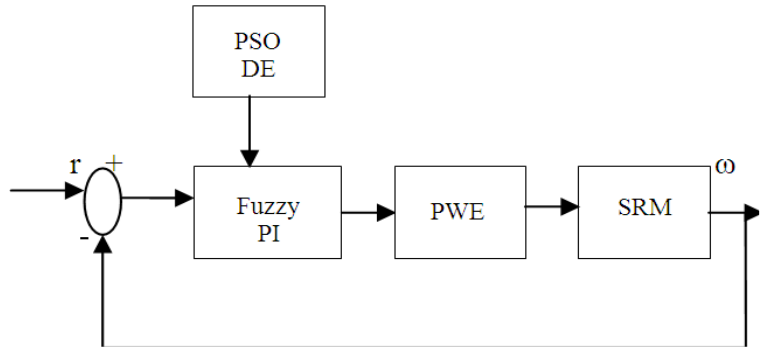

Fig. 1: Optimal fuzzy PI control

$\min _{K} X(K)=\left(1-e^{-\alpha}\right)\left(M_{p}+E_{S S}\right)+e^{-\alpha}\left(t_{s}-t_{r}\right)$

where, $\mathrm{K}$ is $[\mathrm{P}, \mathrm{I}]$ and $\alpha$ is the weighting factor. The performance criterion $\mathrm{X}(\mathrm{K})$ satisfies the designer requirement using the weighting factor $\alpha$ value. $\alpha$ can be set to larger than 0.7 to reduce the overshoot and steady states error or can be set to smaller than 0.7 to reduce the rise time and settling time.

Proposed PSODE-fuzzy PI Controller: In this stduy, a PSO-fuzzy PI controller is used to find the optimal parameters of SRM speed control system. Figure 1 shows the block diagram of optimal fuzzy PI control for the Switched Reluctance Motor.

In the proposed PSODE method, each particle contains two members, $\mathrm{P}$ and I. The search space has two dimensions and particles must 'fly' in a two dimensional space. A combination of DE and PSO is developed by mutation operator of $\mathrm{DE}$ to improve diversity exploration of PSO. Hence, it is named as new hybrid PSO algorithm.

Mathematical model of SRM: Three sets of expression are needed to obtain the mathematical model of SRM: Mechanical equation, Electrical equation and angular speed equation.

The Eq. 12 describes motion of the motor:

$\frac{\mathrm{d} \omega}{\mathrm{dt}}=\frac{1}{\mathrm{j}}\left(\sum_{\mathrm{k}=1}^{\mathrm{q}} \mathrm{T}_{\mathrm{k}}\left(\theta_{\mathrm{k}}, \mathrm{i}_{\mathrm{k}}\right)-\mathrm{T}_{\mathrm{i}}\right)$

The Eq. 13 describes electrical behavior of SRM:

$\frac{\mathrm{d} \psi_{k}\left(\theta_{\mathrm{k}}, \mathrm{i}_{\mathrm{k}}\right)}{\mathrm{dt}}= \pm \mathrm{V}-\mathrm{R}_{\mathrm{k}}$

The angular speed is described by Eq. 14.

$\omega=\frac{\mathrm{d} \theta}{\mathrm{dt}}$ 


\section{RESULTS}

The performance of the proposed controllers are investigated using simulation and simulation is applied to switched reluctance motor. Two different speeds are considered as reference speeds for simulation. The speed $\mathrm{N} 1$ and N2 are 200 and 300 rpm respectively.

Table 1 shows the rule base of fuzzy PI controller. The rule base consists of 49 if-then rules

Optimal PSODE-fuzzy PI response: To control the speed of the Switched Reluctance motor, according to the trials, the following PSO parameters are used to verify the performance of the PSO-fuzzy PI controller parameters:

- Population size: 50;

- $\mathrm{Max} \mathrm{w}=0.6 \min \mathrm{w}=0.1$

- $\mathrm{C} 1=\mathrm{C} 2=1.5$;

- Iteration: 50;

Varying speed at no load: To demonstrate the system performance of controllers, sudden change of reference speed at no load is introduced.

\begin{tabular}{llllllll}
\multicolumn{2}{l}{ Table 1: Fuzzy rules } \\
\hline$\Delta \mathrm{e} / \mathrm{e}$ & NB & NM & NS & ZE & PS & PM & PB \\
\hline NB & NB & NB & NB & NM & NM & NS & ZE \\
NM & NB & NB & NM & NS & NS & ZE & PS \\
NS & NB & NM & NS & NS & ZE & PS & PM \\
ZE & NM & NS & NS & ZE & PS & PS & PM \\
PS & NM & NS & ZE & PS & PS & PM & PB \\
PM & NS & ZE & PS & PS & PM & PB & PB \\
PB & ZE & PS & PM & PM & PB & PB & PB \\
\hline
\end{tabular}

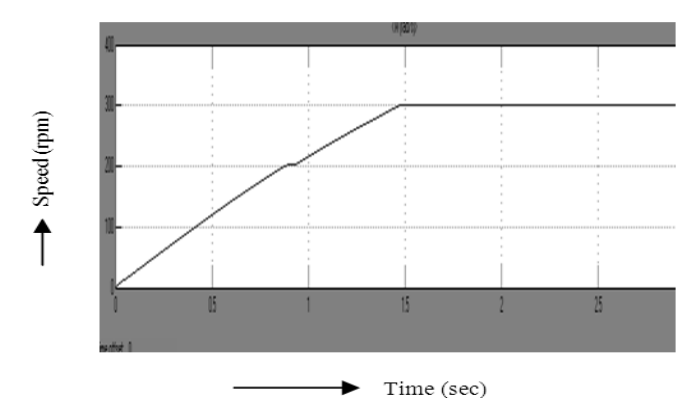

Fig. 2: System output response at no load condition by using fuzzy controller

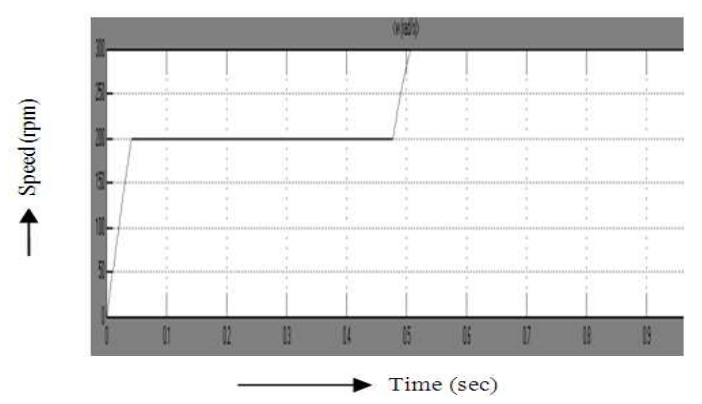

Fig. 3: System output response at no load condition by using fuzzy PI controller
Table 2:Performance analysis of simulation for sudden change in speed at no load condition

\begin{tabular}{llllll}
\hline \multicolumn{5}{c}{ No-load condition } \\
& & \multicolumn{1}{c}{ Fuzzy } & PSO- & PSODE \\
& & Fuzzy & PI & Fuzzy PI & Fuzzy PI \\
\hline Reference Speed & OS (\%) & - & - & - & \\
-200 & ts (s) & 0.8 & 0.045 & 0.04 & 0.035 \\
Speed Increased & OS (\%) & - & - & - & \\
-300 & ts (s) & 0.5 & 0.03 & 0.03 & 0.025 \\
\hline
\end{tabular}

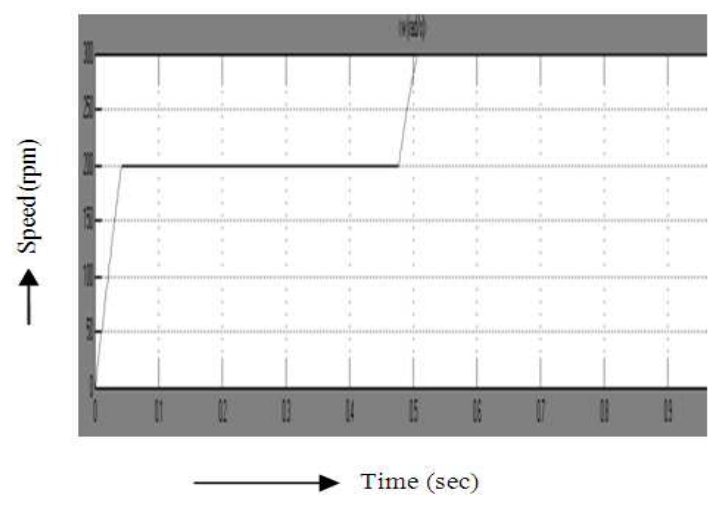

Fig. 4: System output response at no load condition by using PSO based fuzzy PI controller

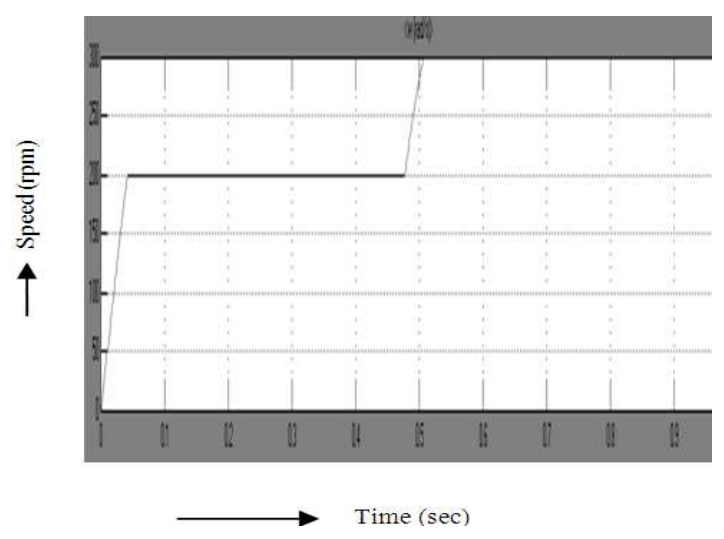

Fig. 5: System output response at no load condition by using PSODE based fuzzy PI controller

The response due to sudden change of reference speed is illustrated in Figures for various controllers. Performance analysis of the simulation for step function and sudden change of speed reference are summarized in Table 2. From the Table 2 and Fig. 2-5, we verify the performance of all the controllers at no load condition with reference speed 200 RPM.

\section{DISCUSSION}

From the verification, it is found that the settling time of fuzzy logic controller is $0.8 \mathrm{sec}$, fuzzy PI controller is $0.045 \mathrm{sec}$, PSO based fuzzy PI controller is $0.040 \mathrm{sec}$ and PSODE based fuzzy PI 


\section{J. Computer Sci., 8 (9): 1473-1477, 2012}

controller is 0.035 . When the speed is increased to 300 RPM, the settling time of fuzzy logic controller is $0.5 \mathrm{sec}$, fuzzy PI controller is $0.030 \mathrm{sec}$, PSO based fuzzy PI controller is $0.0 .030 \mathrm{sec}$ PSODE based fuzzy PI controller is 0.025 . From the above comparison, it is evident that PSODE based fuzzy PI controller performs far better when compared to the other controllers.

From the above tabulation and response curves, it is found the speed of SRM is controlled by various type of controllers and the overshoot is absent in all the controllers. There is better performance in settling time of the speed response of the motor by using Particle swarm optimization and differential evolution based fuzzy PI controller.

\section{CONCLUSION}

For the speed control of switched reluctance motor, fuzzy controller, fuzzy PI controller, PSO optimized fuzzy PI controller and a new hybrid algorithm PDODE optimized fuzzy PI controller have been developed and implemented. From the result comparative analysis of the results, the proposed PSODE optimized fuzzy PI controller has shown better performance in the speed control of switched reluctance motor.

\section{REFERENCES}

Ahmed, F.I., A.M. El-Tobshy, A.A. Mahfouz and M.M.S. Ibrahim, 1997. P-I and I-P controllers in a closed loop for DC motor drives. Proceedings of the Power Conversion Conference Nagaoka, Aug. 3-6, IEEE Xplore Press, Nagaokam, pp: 613-618. DOI: 10.1109/PCCON.1997.638255

Del Valle, Y., G.K. Venayagamoorthy, S. Mohagheghi, J.C. Hernandez and R.G. Harley, 2008. Particle swarm optimization: Basic concepts, variants and applications in power systems. IEEE Trans. Evol. Comput., $\quad$ 12: 71-195. DOI: 10.1109/TEVC.2007.896686

Gaing, Z.L., 2004. A particle swarm optimization approach for optimum design of PID controller in AVR system. IEEE Trans. Energy Conversion, 19: 384-391. DOI: 10.1109/TEC.2003.821821

Kennedy, J. and R. Eberhart, 1995. Particle Swarm Optimization. Proc. IEEE Int. Conf. Neural Net., 4: 1942-1948. DOI: 10.1109/ICNN.1995.488968

Krohling, R.A., H. Jaschek and J.P. Rey, 1997. Designing PI/PID controller for a motion control system based on genetic algorithms. Proceedings of the IEEE International Symposium on Intelligent Control, Jul. 16-97, IEEE Xplore Press, Istanbul, pp. 125-130. DOI: 10.1109/ISIC.1997.626429
Kukolj, D., F. Kulic and E. Levi, 2000. Design of the speed controller for sensor less electric drives based on AI techniques: A comparative study. Artificial Intell. Eng., 14: 65-174. DOI: 10.1016/S0954-1810(00)00010-8

Lawrenson, P.J., J.M. Stephenson, N.N. Fulton, P.T. Blenkinsop and J. Corda, 1980. Variable-speed switched reluctance motors. IEE Proc. B Elec. Power Appli., 127: 253-265. DOI: 10.1049/ipb:19800034

Miller, T.J.E., 1993. Switched reluctance motors and their control. 1st Edn., Magna Physics, Hillsboro, ISBN-10: 0198593872, pp: 216.

Moghbelli, H., G.E. Adams and R.G. Hoft, 1991. Performance of a 10-HP switched reluctance motor and comparison with induction motors. IEEE Trans. Indus. Appli., 27: 531-538. DOI: $10.1109 / 28.81838$

Nagel, N.J. and R.D. Loranz, 2000. Rotating vector methods for smooth torque control of a switched reluctance motor drive. IEEE Trans. Indus. Appli., 36: 540-548. DOI: 10.1109/28.833772

Narmadha, T.V. and T. Thyagarajan, 2010. Fuzzy Logic based position-sensorless speed control of multi level inverter fed pmbldc drive. J. Adv. Inform. Technol., 1: 52-58. DOI: 10.4304/jait.1.1.52-58

Nasri, M., H. Nezamabadi-pour and M. Maghfoori, 2007. A PSO-based optimum design of PID controller for a linear brushless DC motor. World Academy Sci. Eng. Technol.

Pollock, B.W. and C. Williams, 1990. Power convertor circuits for switched reluctance motors with the minimum number of switches. Iee Proc.-B Elec. Power Appli., 137: 373-384.

Santana, J., J.L. Naredo, F. Sandoval, I. Grout and O.J. Argueta, 2002. Simulation and construction of a speed control for a DC series motor. Mechatronics, 12: $1145-1156 . \quad$ DOI: $10.1016 /$ S09574158(02)00019-3

Shun-Chung, W. and Y.H. Liu, 2011. A modified pilike fuzzy logic controller for switched reluctance motor drives. IEEE Trans. Indus. Elect., 58: 18121825. DOI: 10.1109/TIE.2010.2058074

Sousa, G.C.D. and B.K. Bose, 1994. A fuzzy set theory based control for phase-controller converter DC machine drive. IEEE Trans. Indus. Appli., 30: 3444. DOI: $10.1109 / 28.273619$ 